\title{
Evaluating Programmed Artificial Insemination for Cattle Production
}

\author{
Takuya Yoshihara ${ }^{1}$, Yunan $\mathrm{He}^{2}$, Osamu Fukuda ${ }^{3}$ \\ Hiroshi Okumura $^{4}$ and Kohei Arai ${ }^{5}$ \\ Graduate School of Science and Engineering \\ Saga University, Japan \\ Naoki Takenouchi ${ }^{8}$ \\ National Agriculture and Food Research \\ Organization (NARO), Kumamoto, Japan \\ Junki Egashira ${ }^{11}$ \\ Saga Prefectural Livestock Experiment Station \\ Saga, Japan
}

\author{
Iqbal Ahmed ${ }^{6}$ \\ Department of Computer Science \\ and Engineering \\ Kenji Endo ${ }^{7}$ \\ Morinaga Dairy Service Co. Ltd. \\ Tochigi, Japan
}

University of Chittagong, Bangladesh

\author{
Hideo Matsuda ${ }^{9}$ \\ and Tadayuki Yamanouchi ${ }^{10}$ \\ National Livestock Breeding Center, Fukushima, Japan \\ Kenichi Yamashita ${ }^{12}$ \\ The National Institute of Advanced Industrial Science \\ and Technology (AIST), Saga, Japan
}

\begin{abstract}
Cattle productivity in Japan has been declining though livestock farmers and breeders tried to use artificial insemination regularly. The reason behind this declining productivity is the poor evaluation of the applicability of artificial insemination. To address this issue, this research proposes an objective evaluation method to estimate the applicability of programmed Artificial Insemination (pAI). The objective evaluation method tries to estimate the applicability of pAI based on the analysis of various indices from dairy and beef cattle using Bayesian Network Model (BNM). The estimation of the pAI applicability considers 14 and 17 physiological indices for diary and beef cattle respectively. These indices include the basic information (days after childbirth, parity, etc.), diagnosis of appearance, diagnosis of genital organ and the veterinarians' judgments. The overall success rate in estimating the applicability is $89.8 \%$ for $\mathbf{1 0 5 1}$ records of dairy cattle and $\mathbf{9 5 . 6 \%}$ for 1128 records of beef cattle. The proposed method avoids the subjective error in estimating the applicability of pAI. In addition, the experiment revealed that the applicability of pAI can be evaluated even though the number of measure indices is few.
\end{abstract}

Keywords-Bayesian network; programmed artificial insemination; cattle production

\section{INTRODUCTION}

The conception rate of Japanese cattle has been declining for the last 20 years though the livestock companies and veterinaries tried to use artificial insemination regularly [1]. The improvement of conception rate hugely relies on the accurate estimation of estrous cycle. However, the subjective methods of finding estrous cycle sometimes lead to some mistakes and miss the best timing of artificial insemination. The estimation of estrous cycle usually relies on the cattle appearance check or ultrasound image analysis by an experienced inspector. In order to address this issue, many scientists and researchers were trying to use objective indices of a cattle, such as breeding ability, evaluation of dairy cattle conception rate, to estimate the estrous cycle. These studies find many measurement indices that have an relationship with evaluating the productivity of dairy cattle in the industry. In this study, we try to collect these measurement indices of cattle as many as possible and input them to a Bayesian network model (BNM) to estimate the applicability of programmed artificial insemination (pAI). These indices include the basic information (days after childbirth, parity, etc.), the diagnosis of cattle appearance, the diagnosis of genital organ and the uterus condition from the veterinarian's judgment. To collect these data, we got a lot of support from the farmers, the inspectors from dairy company and the veterinarians. With their help, we successfully collected 14 and 16 measurement indices for dairy cattle and beef cattle respectively to build the BNM model. This research discovers that the way of using Bayesian network with many measurement indices achieves more precise estimation of the applicability of pAI in the cattle farming and therefore, assisting the farm management to reduce their overall labor and cost.

The paper layout consists of background checks first, then followed by the selection of cattle indices for the proposed model and the design of BNM model considering selected indices for dairy and beef cattle. Then the validation results of $\mathrm{BNM}$ are presented with brief conclusions.

\section{BACKGROUND CHECKS}

Many studies find many measurement indices that are responsible for evaluating the productivity of dairy cattle in the industry. First of all, understanding the ultrasound image analysis of estrous cycle allows the farm management to troubleshoot the productivity problems. Additionally, these are essential for estrous synchronization program and other productive technologies in the livestock industries [2], [3], [4], [5]. The productivity of the cattle is largely identified by whether the cattle shows regular and normal estrous cycles or not. There are many influential factors for the reproductivity of the cattle farming which are already elaborated by various researchers and veterinarian [6], [7], [8], [9], [10], [11], [12], [13]. Understanding the estrous cycle is the first step for the applicability of pAI and many measurement indices are responsible for it 
[14], [15], [16]. There were many discovered influential indices for the cattle herd management such as, Body Condition Score (BCS), days after calving and or Postpartum Interval (PPI), parity number, ovarian characteristics, uterine blood flow, progesterone level (P4), climate and nutritional factors, etc. [17], [18], [19], [20]. In addition, different species of beef and dairy cattle also plays vital roles in this case. However, finding out the presence of estrous cycle definitely a distinctive index for the applicability of pAI, which will eventually assists the productive management in the cow herd. Many measurement indices including ultrasound image analysis of the presence or absence of estrous cycles are done by some regular data analytical tools of an experienced veterinarian [21], [22], [23], [24], [25]. The usage of ultrasound image analysis, echo data, $\mathrm{BCS}$, sexual excitement sign for cow and heifers are very much biased, costly and error prone to some extent. Additionally, years of experiences and skills are necessary for understanding ultrasound image, echo data to pinpoint the proper time for the applicability of pAI. Some works have been done on the objective measurement of improving productivity using BNM in the cattle industry [15], [16]. However, the number of measurement indices of cattle is only a few in these researches which leaves us room for further improvement.

\section{Measurement Indices and Selection of IMPORTANT INDICES FOR THE MODEL}

Usually, livestock farmers and veterinarians measure various indices of cattle after calving until next pregnancy. The collection of various measurement indices from different sources are shown in Fig. 1. Based on these measured indices, they determine whether pAI is applicable to those cattle or not. For the objective way to analysis, 1051 data (99 dairy cattle) collected from Morinaga Rakunou Co., Ltd. are used for dairy cattle and all this data has 60 measurement indices. On the other hand, 1128 data (71 beef cattle) gathered from Saga Livestock Research Laboratory are used and, in that cases, there are 16 measurement indices. For the data of dairy cattle, a large number of indices are used. But we only select the indexes which are directly related to the applicability of pAI using mosaic plot (Fig. 2) as a primary stage of creating BNM model. In [15], the relationship between the maximum size of corpus luteum and applicability of pAI elaborated shows the importance of pAI for increasing the productivity. Table I lists 14 measurement indices used for the analysis of dairy cattle, and Table II gives 16 measurement indices used for the analysis of beef cattle. Representative and considerable measurement indices will be introduced briefly below.

Among the many factors that have an effect on cattle productivity, the most widely used for herd management is BCS which is defined as "an effective management tool to estimate the energy reserves" of a cow [27], [28], [29]. There are many certified systems for measuring BCS, which varies in different countries [27], [28]. Using BCS to evaluate cattle does not require any special equipment and can be conducted anytime during the year. Poor body condition is associated with reduced income per cow, increased postpartum interval, increased dystocia, and decreased weaning weight. The most common and widely used (USA and Japan) BCS scale ranges from 1 to 5 with 0.25 increments [26]. BCS is related with various factors of cattle, for example postpartum interval (PPI), parity number, RFS, etc. [7], [22], [27] and the reliability

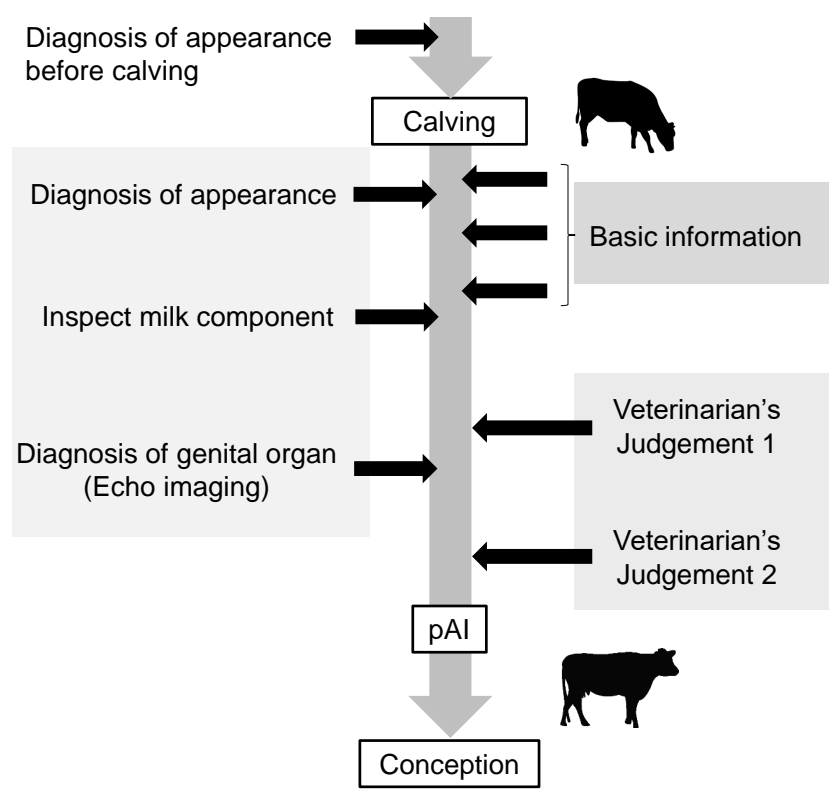

Fig. 1. The steps for collecting various measurement indices in beef and dairy cattle in Japan

of BCS measurement is still questionable to some extent. In the case of beef cattle, BCS is divided into two items: BCS (Body surface) and BCS (Pelvis) in Table II. Although it has somewhat different criteria, it can be considered roughly as BCS for dairy cattle.

Days after calving shown in the first column of Table I and Table II indicates how many days have been passed since the last calving. Since productivity improves as the number of days from the last calving to the next calving is shortened, decreasing days after calving is important.

The objective of this research is to reveal the optimum factors for the pAI applicability using BNM in Japanese cattle. Using BNM for analyzing the applicability of pAI individually in dairy and beef cattle is the most distinctive findings in this field. Moreover, the applicability of pAI using BNM is evaluated even though the number of measurement indices are few.

\section{DESIGNING BAYESIAN NETWORK MODEL (BNM) WITH IDENTIFIED DAIRY AND BEEF CATTLE MEASUREMENT INDICES}

Bayesian network model (BNM) is a type of graphical model based on Bayesian theory for probability computations. It can reveal the causal relationship by representing conditional dependency using edges in an cyclic directed graph (Fig. 3). Also, by making probabilistic reasoning, it is possible to predict the likelihood and possibility of complicated events. For example, the conditional probability between the random variables $X_{i}, X_{j}$ is expressed as $X_{i} \rightarrow X_{j}$ in the Bayesian network. Generally, the probability that another event $x_{2}$ occurs under the condition that a certain event $x_{1}$ has occurred is referred to as a conditional probability and can be expressed as 


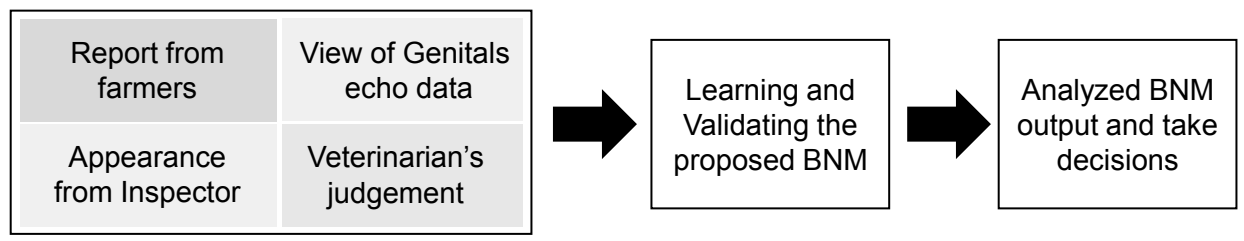

Fig. 2. Analysis of pAI and size of corpus luteum, partial adoption from [15]

TABLE I. MEASUREMENT INDiCES OF DAIRY CATtLE

\begin{tabular}{|l|l|l|l|}
\hline \multicolumn{1}{|c|}{ Basic Information } & Diagnosis of Appearance & \multicolumn{1}{|c|}{ Diagnosis of Genital Organ } & Veterinarian's Judgment \\
\hline Days after Childbirth & BCS & Maximum size of Corpus Luteum & Pregnancy Judgement \\
Parity & RFS & Blood flow in Luteum & Functional Corpus Luteum \\
Sexual Excitement Sign & Body Shape & Disorder in genital organ & Uterus Condition \\
Times of Artificial Insemination & Lochia & & \\
\hline
\end{tabular}

TABLE II. MEASUREment Indices of BeEF CATtle

\begin{tabular}{|l|l|l|l|}
\hline \multicolumn{1}{|c|}{ Basic Information } & Diagnosis of Appearance & \multicolumn{1}{|c|}{ Diagnosis of Genital Organ } & Veterinarian's Judgment \\
\hline Days after Childbirth & BCS (Body surface) & Maximum size of Corpus Luteum & Remaining in Uterus \\
Parity & BCS (Pelvis) & Blood flow in Luteum & Uterus abnormality \\
Recurrence of Estrus & RS & Number of Follicle & Uncured puerperalism \\
Previous Childbirth Condition & Lochia & Ovarian abnormality & \\
& Uncured Lameness & & \\
\hline
\end{tabular}

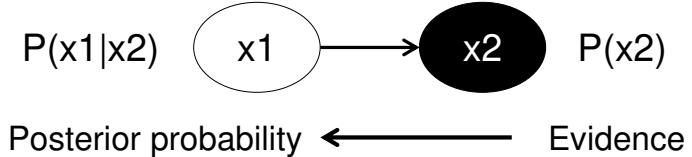

Fig. 3. The basic principle of Bayesian Network

$$
P\left(x_{1} \mid x_{2}\right)=\frac{P\left(x_{1}\right) P\left(x_{2} \mid x_{1}\right)}{P\left(x_{2}\right)}
$$

Here, by using Bayes' theorem, it is possible to obtain $P\left(x_{1} \mid x_{2}\right)$ which is the probability (posterior probability) that $x_{1}$ will occur based on the condition that $x_{2}$ has already occurred. Thus, when the result $x_{2}$ is obtained, it is found that the cause is $x_{1}$.

The proposed method considers four basic information collected from livestock farmers, then four indices from experienced inspectors about the appearance of the cattle. After that, four measurement indices of echo data from the genital organ and veterinarian's judgment are considered. The proposed BNM model is shown in Fig. 4.

The proposed BNM is designed and generated using Bayonet 6 software tool which is developed by AIST, Japan. The data are also visualized using the JMP data analytical tool. The overall proposed work is illustrated in Fig. 5. As shown in the figure, the total posterior probability of the applicability of the pAI is calculated from basic information (days after calving, estrus signs, parity number, times of artificial insemination), appearance indices (BCS, body shape, RFS, lochia), views of genitals or echo data (maximum luteal size, luteal blood

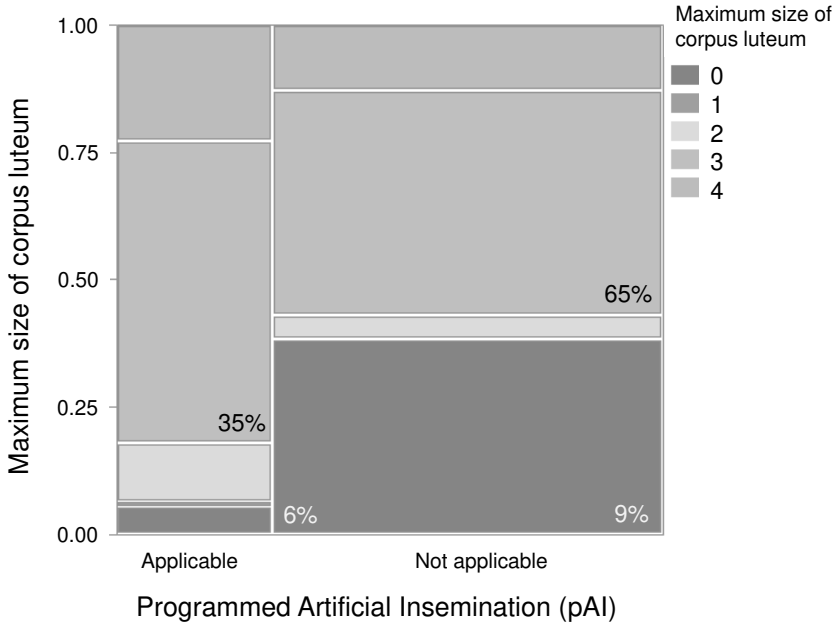

Fig. 4. The proposed BNM of the applicability of pAI in Japanese Cattle

flow, genital abnormalities) and veterinarian's judgment (uterus condition, pregnancy judgment).

\section{VERIFICATION OF FINDINGS}

\section{A. Verification Conditions}

For the verification purpose, a cross-validation test of leave100 -out approach is performed. We first randomly select 100 samples from the dataset and use it as validation data, and then create the proposed BNM with the remaining data. This step is repeated to calculate the average accuracy and confirm 


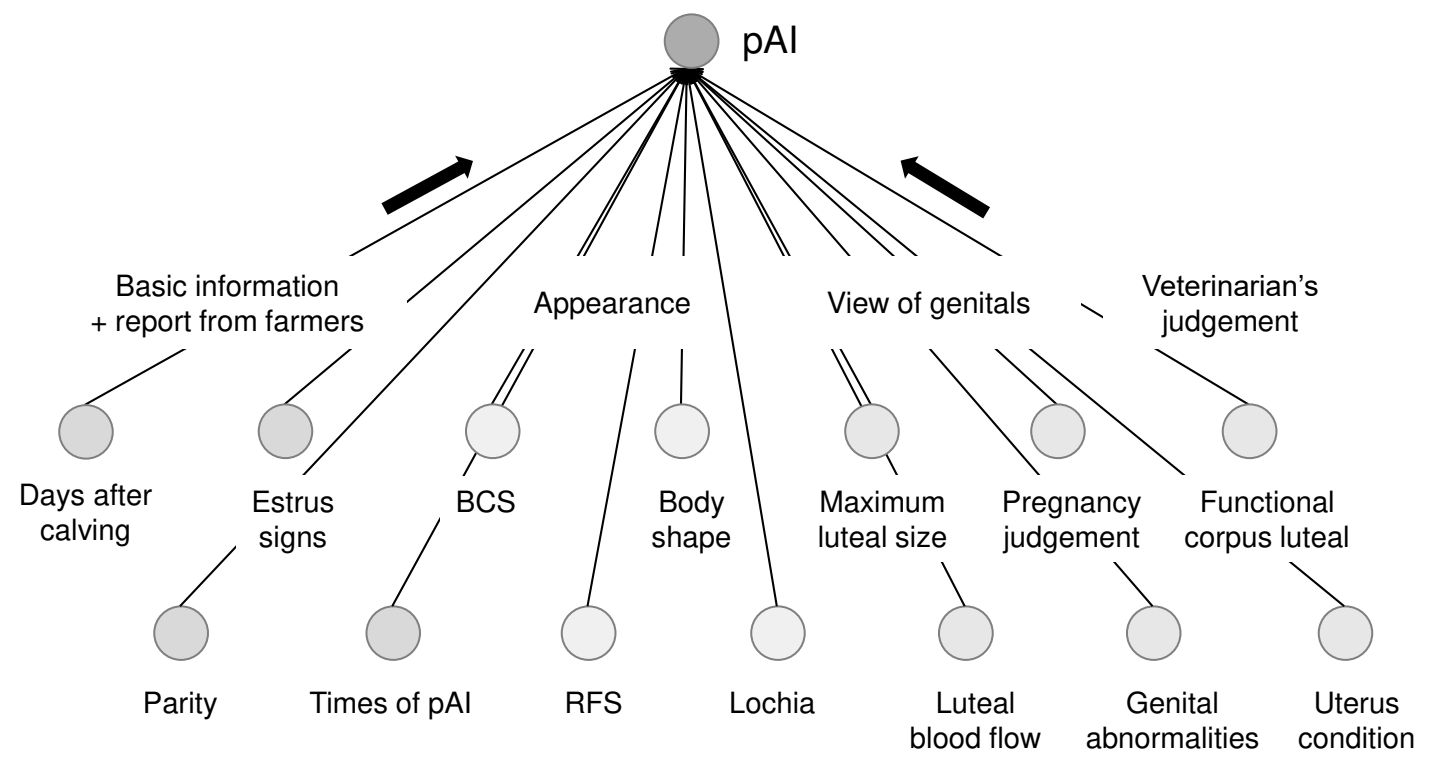

Fig. 5. The overall proposed work

TABlE III. Summary Data of Diary CATtLE

\begin{tabular}{|c|c|c|c|c|}
\hline & Ave. & S.D. & Max. & Min. \\
\hline Days after childbirth & 127.7 & 85.7 & 467.0 & 1.0 \\
\hline Parity & 2.5 & 1.8 & 9.0 & 1.0 \\
\hline BCS & 2.6 & 0.3 & 4.5 & 2.0 \\
\hline RFS & 2.4 & 0.7 & 4.0 & 1.0 \\
\hline
\end{tabular}

TABLE IV. SumMARY DATA OF BEEF CATTLE

\begin{tabular}{|c|c|c|c|c|}
\hline & Ave. & S.D. & Max. & Min. \\
\hline Days after childbirth & 56.0 & 34.4 & 395.0 & 5.0 \\
\hline Parity & 2.4 & 1.4 & 9.0 & 1.0 \\
\hline BCS (Body surface) & 2.8 & 0.3 & 3.75 & 2.0 \\
\hline BCS (Pelvis) & 2.9 & 0.3 & 3.75 & 1.5 \\
\hline RS & 3.4 & 0.2 & 3.5 & 2.5 \\
\hline
\end{tabular}

the validity of the analysis. The data used for verification is shown in Table III and IV.

\section{B. Findings / Results}

Dairy Cattle: For dairy cattle, Table V represents the verification results of the model for evaluating the applicability of pAI. "Applicable" and "Not applicable" in the first row of the table are the decisions based on the estimated result of proposed model while the first column are Veterinarian's decisions ( $\mathrm{A}=$ Applicable, NA= Not applicable). Because of missing values, the number of records used to validate the model was 1051. Among the individuals which are judged as "Applicable" by Veterinarian, 79.9\% of them are judged as "Applicable" in the proposed model. Also, 92.1\% are judged as "Not applicable" in the same model. The overall accuracy rate achieved $89.8 \%$ and the average log likelihood was 0.2425 .

Table VI shows the results from the similar analysis while not considering echo data from the veterinarian. Without echo
TABLE V. VERIFICATION RESUlts OF DAIRY CATTLE WITH ALL INDICES

\begin{tabular}{|c|c|c|c|c|}
\hline \multirow{2}{*}{} & \multicolumn{2}{|c|}{ Not applicable (NA) } & \multicolumn{2}{c|}{ Applicable (A) } \\
\cline { 2 - 5 } & Records & Rate (\%) & Records & Rate (\%) \\
\hline NA & 780 & 92.1 & 67 & 7.9 \\
\hline A & 41 & 20.1 & 163 & 79.9 \\
\hline
\end{tabular}

TABLE Vi. VERIFICATION RESUlts of DAIRY CATTLE Without ECHO DATA

\begin{tabular}{|c|c|c|c|c|}
\hline \multirow{2}{*}{} & \multicolumn{2}{|c|}{ Not applicable (NA) } & \multicolumn{2}{c|}{ Applicable (A) } \\
\cline { 2 - 5 } & Records & Rate (\%) & Records & Rate (\%) \\
\hline NA & 758 & 82.3 & 163 & 17.7 \\
\hline A & 63 & 48.1 & 68 & 51.9 \\
\hline
\end{tabular}

data, the proposed model showed slightly lower accuracy (78.6\%, average log likelihood 0.4157 ) for the dairy cattle. The view of genitals and veterinarian's judgments are not considered in this case.

Beef Cattle: For beef cattle, 16 measurement indices (Table II) are used. Fig. 4 shows the proposed model and Table VII represents the verification results for the decision of applicability of pAI or not. "Applicable" and "Not applicable" in the first row of the table are judgments based on the estimated results of this model, and in the first column are Veterinarian's judgments. Because of missing values, the number of records used to validate the model was 1128 . Among the individuals which are judged as "Applicable" by Veterinarian, 97.1\% of them are judged as "Applicable" in the proposed model. Also, $92.0 \%$ are judged as "Not applicable" in the same model. The overall accuracy rate was $95.6 \%$ and the average log likelihood was 0.2181. Table VIII illustrates the accuracy rate of beef cattle $(90.7 \%$, average $\log$ likelihood 0.2509$)$ for evaluating the applicability of pAI with echo data. 

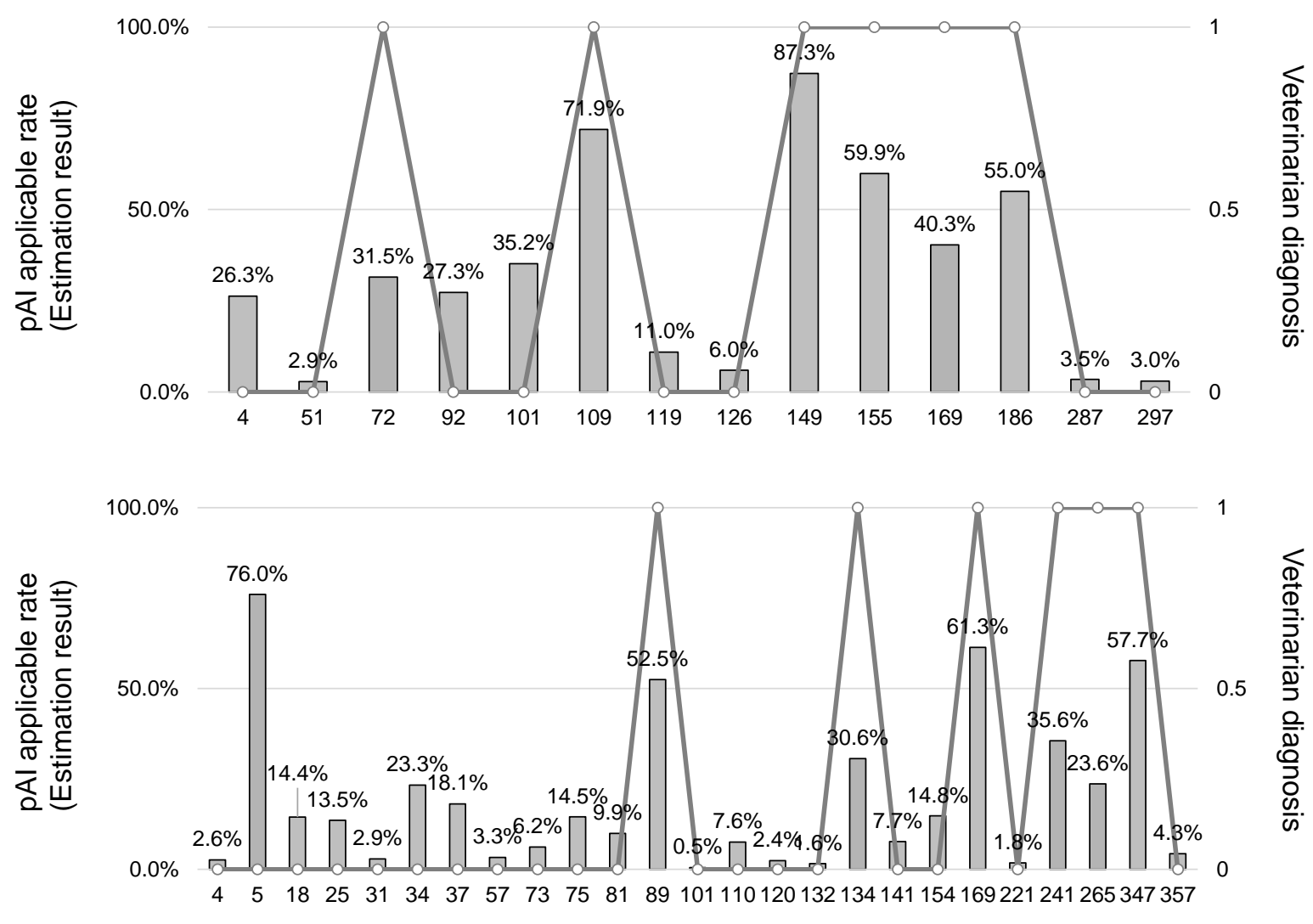

Day after calving

ए pAl applicable rate (Estimation) $\quad-\infty$ pAl applicable rate (Veterinarian diagnosis)

Fig. 6. Comparison between pAI applicability rate estimation by proposed BNM and pAI applicability rate by Veterinarian

TABLE VII. VERIFICATION RESUlts OF BEEF CATTLE With ALL INDICES

\begin{tabular}{|c|c|c|c|c|}
\hline \multirow{2}{*}{} & \multicolumn{2}{|c|}{ Not applicable (NA) } & \multicolumn{2}{c|}{ Applicable (A) } \\
\cline { 2 - 5 } & Records & Rate (\%) & Records & Rate (\%) \\
\hline NA & 286 & 92.0 & 25 & 8.0 \\
\hline A & 24 & 2.9 & 793 & 97.1 \\
\hline
\end{tabular}

TABLE ViII. Verification Results of BeEF CATtLe without Echo DATA

\begin{tabular}{|c|c|c|c|c|}
\hline \multirow{2}{*}{} & \multicolumn{2}{|c|}{ Not applicable (NA) } & \multicolumn{2}{c|}{ Applicable (A) } \\
\cline { 2 - 5 } & Records & Rate (\%) & Records & Rate (\%) \\
\hline NA & 263 & 83.2 & 53 & 16.8 \\
\hline A & 48 & 5.9 & 765 & 94.1 \\
\hline
\end{tabular}

The summary of the proposed BNM analysis is represented in Table IX. The overall estimation for the applicability of our proposed model is further presented using a time series graph. It shows that the objective estimation for the applicability of pAI is much better than veterinarian's judgments in the cattle feed industry. Fig. 6 depicts the overall comparison of this research findings. In the Fig. 6, the red bar graph represents the pAI applicability rate of the proposed model which is different
TABLE IX. SUMMARY OF THE ANALYSIS

\begin{tabular}{|c|c|c|}
\hline Types of Cattle & Index & Accuracy(\%) \\
\hline \multirow{2}{*}{ Dairy Cattle } & All indices & 89.8 \\
\cline { 2 - 3 } & Without Echo data & 78.6 \\
\hline \multirow{2}{*}{ Beef Cattle } & All indices & 95.6 \\
\cline { 2 - 3 } & Without Echo data & 90.7 \\
\hline \multicolumn{2}{|c|}{ Overall Average Accuracy } & 87.7 \\
\hline
\end{tabular}

from veterinarian's diagnosis.

\section{CONCLUSiOn AND Future Work}

This study finds out an objective method to estimate whether pAI is applicable to the cattle or not. It is achieved by analyzing various of measurement indices of beef and dairy cattle using BNM. The overall accuracy rate of the proposed method exceeds $85 \%$. This objective estimation methods for the applicability of pAI using BNM guide to an eccentric idea to overcome the subjective measurement error of the applicability of artificial insemination in the cattle production in Japan and as well as abroad. In the future, we would like to develop graphical user interfaces for the livestock farmers to help them estimate the applicability of pAI. 


\section{ACKNOWLEDGMENT}

This research work is funded and supported by Ministry of Agriculture, Forestry and Fisheries(MAFF), Japan under the project name of "Development of technology for enhancement of livestock lifetime productivity by improving fertility through assisted reproduction". Authors would like to gratitude MAFF for their full support and contribution to accomplish the research.

\section{REFERENCES}

[1] Report of National Livestock Breeding Center, Japan, 2016. Website: http://www.nlbc.go.jp/en/, Accessed January.

[2] Whittier, J.C., 1993. Reproductive anatomy and physiology of the cow. Extension publications (MU).

[3] Burns, P.D., 2015. The Dairy Cow Heat Cycle. Colorado State University, Accessed December.

[4] Parish, J.A., Larson, J.E. and Vann, R.C. 2010. The Estrous cycle of Cattle. Mississippi State University in cooperation with US Department of Agriculture, Publication, No. 2616.

[5] Perry, G., 2015. The Bovine Estrous Cycle-FS921A. South Dakota State University-Cooperative Extensive Service USDA, Accessed December.

[6] Walker, J. and Perry, G., 2007. Cow Condition and Reproductive Performance. Proceeding of The Range Beef Cow Symposium XX, Colorado, USA

[7] Pfeifer, L.F.M., Leal, S.D.C.B.D., Schneider, A., Schmitt, E. and Corrêa, M.N., 2012. Effect of the ovulatory follicle diameter and progesterone concentration on the pregnancy rate of fixed-time inseminated lactating beef cows. Revista Brasileira de Zootecnia, 41(4), pp.1004-1008.

[8] Matsui, M. and Miyamoto, A., 2009. Evaluation of ovarian blood flow by colour Doppler ultrasound: practical use for reproductive management in the cow. The Veterinary Journal, 181(3), pp.232-240.

[9] Zacarias, T.A., Sena-Netto, S.B., Mendonca, A.S., Franco, M.M. and Figueiredo, R.A., 2015. Ovarian follicular dynamics in 2 to 3 months old Nelore calves (Bos taurus indicus). Embrapa Recursos Genéticos e Biotecnologia-Artigo em periódico indexado (ALICE).

[10] Perry, G.A., Smith, M.F., Roberts, A.J., MacNeil, M.D. and Geary, T.W., 2007. Relationship between size of the ovulatory follicle and pregnancy success in beef heifers. Journal of animal science, 85(3), pp.684-689.

[11] Honnens, A., Voss, C., Herzog, K., Niemann, H., Rath, D. and Bollwein, H., 2008. Uterine blood flow during the first 3 weeks of pregnancy in dairy cows. Theriogenology, 70(7), pp.1048-1056.

[12] Campanile, G., Neglia, G., Di Palo, R., Gasparrini, B., Pacelli, C., Michael, J.D. and Zicarelli, L., 2006. Relationship of body condition score and blood urea and ammonia to pregnancy in Italian Mediterranean buffaloes. Reproduction Nutrition Development, 46(1), pp.57-62.

[13] Perry, G.A., Swanson, O.L., Larimore, E.L., Perry, B.L., Djira, G.D. and Cushman, R.A., 2014. Relationship of follicle size and concentrations of estradiol among cows exhibiting or not exhibiting estrus during a fixedtime AI protocol. Domestic animal endocrinology, 48, pp.15-20.

[14] Arai, K., Suzaki, N., Ahmed, I., Fukuda, O., Okumura, H., Endo, K. and Yamashita, K., 2017. Method for Productive Cattle Finding with Estrus Cycle Estimated with BCS and Parity Number and Hormone Treatments based on a Regressive Analysis. Journal of Advanced Computer Science and Applications (IJACSA), 8(9), pp.191-196.
[15] Yoshihara, T., Ahmed, I., Fukuda, O., Okumura H., Endo, K., and Takenouchi N., 2019. Applicability of Programmed Artificial Insemination (pAI) for evaluting Japnese Cattle Production using Bayesian Network Model (BNM). Proceedings of the 24th International Symposium on Artificial Life and Robotics, pp.1117-1120.

[16] Ahmed, I., Endo, K., Fukuda, O., Arai, K., Okumura, H. and Yamashita, K., 2016. Japanese Dairy Cattle Productivity Analysis using Bayesian Network Model (BNM). International Journal of Advanced Computer Science and Applications, 7(11), pp.31-37.

[17] Kellogg, W., 2016. Body Condition Scoring with dairy cattle- FAS4008. University of Arkansas, Accessed January.

[18] Bewley, J.M. and Schutz, M.M., 2008. An interdisciplinary review of body condition scoring for dairy cattle. The professional animal scientist, 24(6), pp.507-529.

[19] Castro, F.C., Porcayo, J.O., Ake-Lopez, R.J., Monforte, J.G.M. and Montes-Perez, R.C., 2013. Effect of body condition score on estrus and ovarian function characteristics of synchronized beef-master cows. Tropical and Subtropical Agroecosystems, 16(2).

[20] Yamada, K., Nakao, T. and Isobe, N., 2003. Effects of body condition score in cows peripartum on the onset of postpartum ovarian cyclicity and conception rates after ovulation synchronization/fixed-time artificial insemination. Journal of reproduction and development, 49(5), pp.381388

[21] Takagi, M., Yamagishi, N., Lee, I.H., Oboshi, K., Tsuno, M. and Wijayagunawardane, M.P.B., 2005. Reproductive management with ultrasound scanner-monitoring system for a high-yielding commercial dairy herd reared under stanchion management style. Asian-australasian journal of animal sciences, 18(7), pp.949-956.

[22] Adams, G.P. and Singh, J., 2011. Bovine bodyworks: Ultrasound imaging of reproductive events in cows. Advances in Dairy Technology, 23, pp.239-54.

[23] Viana, J.H.M., Arashiro, E.K.N., Siqueira, L.G.B., Ghetti, A.M., Areas, V.S., Guimarães, C.R.B., Palhao, M.P., Camargo, L.S.A. and Fernandes, C.A.C., 2013. Doppler ultrasonography as a tool for ovarian management. Animal Reproduction, 10(3), pp.215-222.

[24] Fricke, P.M. and Lamb, G.C., 2002. Practical applications of ultrasound for reproductive management of beef and dairy cattle. Proceedings: Applied Reproductive Strategies in Beef Cattle, Manhattan, KS, pp.22845 .

[25] Lamb, G.C., Dahlen, C.R. and Brown, D.R., 2003. Reproductive ultrasonography for monitoring ovarian structure development, fetal development, embryo survival, and twins in beef cows. The Professional Animal Scientist, 19(2), pp.135-143.

[26] Ferguson, J.D., Galligan, D.T. and Thomsen, N., 1994. Principal descriptors of body condition score in Holstein cows. Journal of dairy science, 77(9), pp.2695-2703. Vancouver

[27] DeJarnette, M., 2004. Estrus synchronization: a reproductive management tool. Select Sires inc. www. selectsires. com. Retrieved on, 31(07), p.2012.

[28] Burkholder, W.J., 2000. Use of body condition scores in clinical assessment of the provision of optimal nutrition. Journal of the American Veterinary Medical Association, 217(5), pp.650-654.

[29] Fukuda, O., Tsuji, T. and Kaneko, M., 2000. A human supporting manipulator based on manual control using EMG signals. Journal of the Robotics society of Japan, 18(3), pp.387-394. 